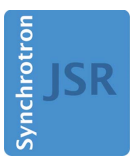

JOURNAL OF SYNCHROTRON RADIATION

ISSN 1600-5775

Received 12 January 2015

Accepted 17 May 2015

Edited by J. F. van der Veen

Keywords: scanning hard X-ray nanoprobe; hierarchical length-scale imaging; multimodal techniques; spectro-microscopy; morphology.

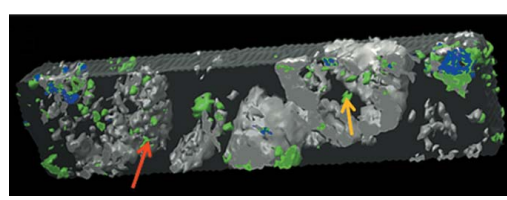

OPEN $\odot A C C E S S$

\section{Optical design and multi-length-scale scanning spectro-microscopy possibilities at the Nanoscopium beamline of Synchrotron Soleil}

\author{
Andrea Somogyi, ${ }^{\mathrm{a} *}$ Kadda Medjoubi, ${ }^{\mathrm{a}}$ Gil Baranton, ${ }^{\mathrm{a}}$ Vincent Le Roux, ${ }^{\mathrm{a}}$ \\ Marc Ribbens, ${ }^{a}$ François Polack, ${ }^{a}$ Pascal Philippot ${ }^{b}$ and Jean-Pierre Samama ${ }^{a}$
}

\footnotetext{
${ }^{a}$ Synchrotron Soleil, BP 48, Saint-Aubin, 91192 Gif-sur-Yvette, France, and ${ }^{\mathbf{b}}$ Géobiosphère Actuelle and Primitive, Institut de Physique du Globe de Paris, Sorbonne Paris Cité, Université Paris Diderot, CNRS, 75238 Paris, France.

*Correspondence e-mail: somogyi@synchrotron-soleil.fr
}

The Nanoscopium 155 m-long beamline of Synchrotron Soleil is dedicated to scanning hard X-ray nanoprobe techniques. Nanoscopium aims to reach $\leq 100 \mathrm{~nm}$ resolution in the 5-20 keV energy range for routine user experiments. The beamline design tackles the tight stability requirements of such a scanning nanoprobe by creating an overfilled secondary source, implementing all horizontally reflecting main beamline optics, applying high mechanical stability equipment and constructing a dedicated high-stability building envelope. Multitechnique scanning imaging and tomography including X-ray fluorescence spectrometry and spectro-microscopy, absorption, differential phase and darkfield contrasts are implemented at the beamline in order to provide simultaneous information on the elemental distribution, speciation and sample morphology. This paper describes the optical concept and the first measured performance of the Nanoscopium beamline followed by the hierarchical lengthscale multi-technique imaging experiments performed with dwell times down to $3 \mathrm{~ms}$ per pixel.

\section{Introduction}

Advanced scanning hard X-ray nanoprobe techniques provide powerful tools for probing heterogeneous complex systems down to the nanometre-scale with high elemental and structural sensitivity (Holt et al., 2013; Kaulich et al., 2011; Martinez-Criado et al., 2014; Vogt \& Lanzirotti, 2013). In recent years significant progress has been reported in the development of focusing optics (Boye et al., 2009; Koyama et al., 2012; Krüger et al., 2012; Mimura et al., 2009; Yan et al., 2011; Yan \& Chu, 2013; Vila-Comamala et al., 2011; Mohacsi et al., 2014), sample positioning (Holler et al., 2012, 2014; Kim et al., 2013; Nazaretski et al., 2013, 2015), detector technology (Johnson et al., 2012; Medjoubi et al., 2013; Ryan et al., 2009) and imaging methodologies (Hornberger et al., 2008; Menzel et al., 2010; Thibault \& Menzel, 2013). These developments are triggering the construction of new state-of-the-art scanning hard X-ray nanoprobes aiming to reach down to $10 \mathrm{~nm}$ spatial resolution [e.g. a non-complete list of such beamlines: De Andrade et al. (2011, 2014), Chu (2010), Nazaretski et al. (2015), Maser et al. (2013), Schroer et al. (2010), Somogyi et al. (2013), Winarski et al. (2012), Chen et al. (2014), ID16A, ID16B and ID13 at the ESRF'; I14 at Diamond Light Source $\left.^{2}\right]$. The current light source construction projects like

\footnotetext{
${ }^{1}$ http://www.esrf.eu/home/UsersAndScience/Experiments/Beamlines/content/ content/id13.html; http://www.esrf.eu/UsersAndScience/Experiments/Imaging /ID16A; http://www.esrf.eu/UsersAndScience/Experiments/Imaging/ID16B.

${ }^{2}$ http://www.diamond.ac.uk/Beamlines/Spectroscopy/I14.html.
} 
NSLS-II, MAX-IV or the upgrades of the ESRF and APS aiming for ultra-low-emittance sources will open new dimensions in the development of such nanoprobes (de Jonge et al., 2014). One of the important issues in modern microscopy development is the combination of high resolution with the possibility of imaging in three dimensions, because the 3D nanostructure of an investigated specimen has basic influence on its biological, chemical and physical properties.

The Nanoscopium beamline of Synchrotron Soleil (Somogyi et al., 2011, 2013) is dedicated to such scanning multi-technique imaging in the $5-20 \mathrm{keV}$ energy range. The beamline aims, as an ultimate goal, to provide high-sensitivity elemental and sample morphology mapping with down to $30 \mathrm{~nm}$ spatial resolution by fast scanning spectro-microscopy combined with absorption, differential phase contrast and dark-field imaging, and coherent imaging techniques. Clearly, overall stability issues are of key importance when aiming for nanometre spatial resolution (Simos et al., 2011; Li et al., 2011; Igarashi et al., 2008). This is especially important for scanning techniques, where robust beam stability matching the aimed spatial resolution is required during typical data collection of several hours. As such, scanning X-ray nanoprobe beamlines must apply overall design considerations that tackle the stability of the source, beamline optics, end-station and beamline envelope in an even-handed way. At Nanoscopium the optical design aims to create a high-stability nanobeam by: an overfilled secondary source, an all horizontally reflecting main beamline optics and a comprehensive stability management, which will be the subject of a future publication.

The typical scientific fields of the beamline cover biology and life sciences, earth and environmental sciences, geobiology and bio-nanotechnology. The beamline is especially well suited for studies seeking information about highly heterogeneous systems at multiple length-scales also in natural or operando conditions. In this paper we report on the optical design of Nanoscopium (Somogyi et al., 2010) together with the measured operational characteristics. Then, the performance of multimodal and multi-scale fast-scanning imaging and 3D tomography is presented, including X-ray fluorescence, absorption-contrast, differential phase contrast and dark-field techniques performed with dwell times down to milliseconds per pixel.

\section{Beamline design}

The Nanoscopium $155 \mathrm{~m}$-long scanning hard X-ray nanoprobe beamline shares, in canted geometry, the L13 source straight section with the Anatomix full-field imaging beamline. A schematic beamline layout is shown in Fig. 1 and the main beamline characteristics are listed in Table 1. The undulator, the front-end (FE) and the pre-focusing mirrors (M1, M2) are located in lead-shielded hutches
Table 1

Characteristics of the Nanoscopium beamline.
Source type

Undulator period

Number of undulator periods

Main beamline mirrors

Monochromator

Energy range

Energy resolution

Measured beam size

at the sample

Aimed spatial resolution

\author{
Cryo-cooled U18 $\mathrm{Pr}_{2} \mathrm{Fe}_{14} \mathrm{~B}$ permanent-magnet \\ undulator \\ $18 \mathrm{~mm}$ \\ 107 \\ M1: horizontal reflecting, sagittal focusing \\ M2: horizontally reflecting, tangential focusing \\ Horizontally reflecting, Si(111) DCM \\ Horizontally reflecting DMM, future upgrade \\ 5-20 keV \\ $\sim 1 \times 10^{-4}$ (DCM) \\ $75-250 \mathrm{~nm}$ depending on the energy and \\ secondary slit size \\ $\mu \mathrm{m}-30 \mathrm{~nm}$ range
}

in the synchrotron building, while the monochromators, the secondary source defining aperture and the experimental hutches are situated in a dedicated building extension (Fig. 1). All hutches are thermally isolated and are equipped with $\pm 0.1 \mathrm{~K}$ temperature control.

\subsection{X-ray source and thermal power management}

The beamline uses a $2 \mathrm{~m}$-long cryo-cooled $\mathrm{U} 18 \mathrm{Pr}_{2} \mathrm{Fe}_{14} \mathrm{~B}$ permanent-magnet prototype undulator (Benabderrahmane et al., 2012). At $10 \mathrm{keV}$, the produced X-ray source of elliptical cross-section has $S_{\mathrm{v}} \times S_{\mathrm{h}}=10 \mu \mathrm{m} \times 265 \mu \mathrm{m}$ r.m.s. vertical and horizontal dimensions and $S_{\mathrm{v}}{ }^{\prime} \times S_{\mathrm{h}}{ }^{\prime}=9 \mu \mathrm{rad} \times 32 \mu \mathrm{rad}$ r.m.s. angular divergence. The spectrum of the undulator was measured through a $100 \mu \mathrm{m} \times 100 \mu \mathrm{m}$ slit-opening situated at $\sim 76 \mathrm{~m}$ distance from the source defining a $1.3 \mu \mathrm{rad}$ emission cone angle (Fig. 2a). The $5-20 \mathrm{keV}$ energy region is covered by the third to 13th undulator harmonics in the $5.5-8 \mathrm{~mm}$ gap range (Fig. 2b). For X-ray absorption spectrometry measurements, micrometre-precision undulator gapscan is necessary due to the narrow energy bandwidth of the odd harmonics (i.e. $\sim 52 \mathrm{eV}$ FWHM of the fifth harmonics at $5.5 \mathrm{~mm}$ gap).

The thermal power management on the optical elements is ensured by the $800 \mu \mathrm{m} \times 800 \mu \mathrm{m}$ front-end collection aperture (FEA), the white beam slits and the high-heat-load beamline filters (Fig. 1). The FEA intercepts the horizontal beam-tails while it lets through the total vertical beam limiting
Synchrotron building
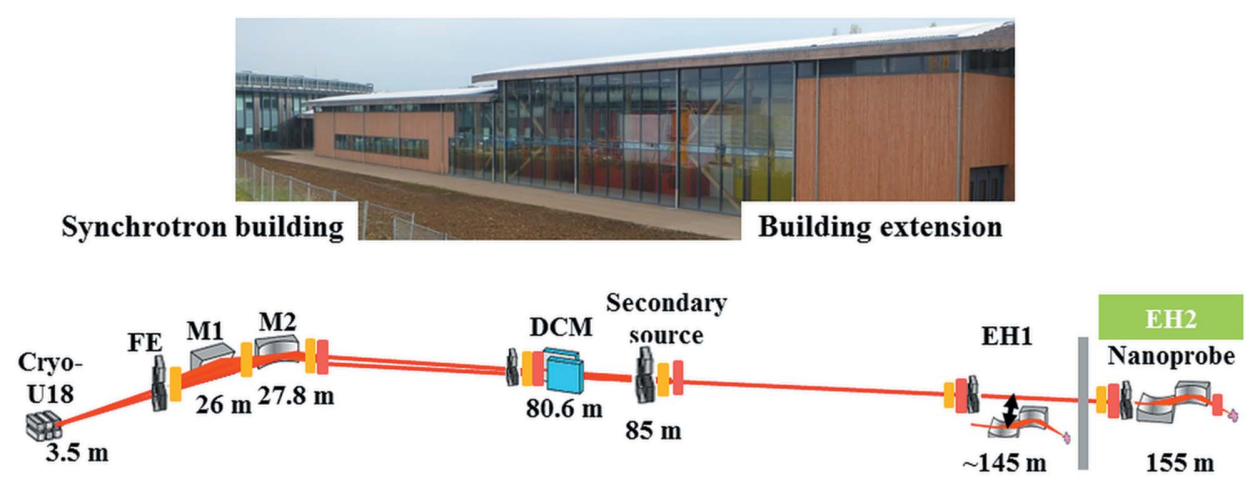

Figure 1

Slits XBPM Imagers

The building extension of the long nano-imaging beamlines. The schematic layout of Nanoscopium is shown underneath. 


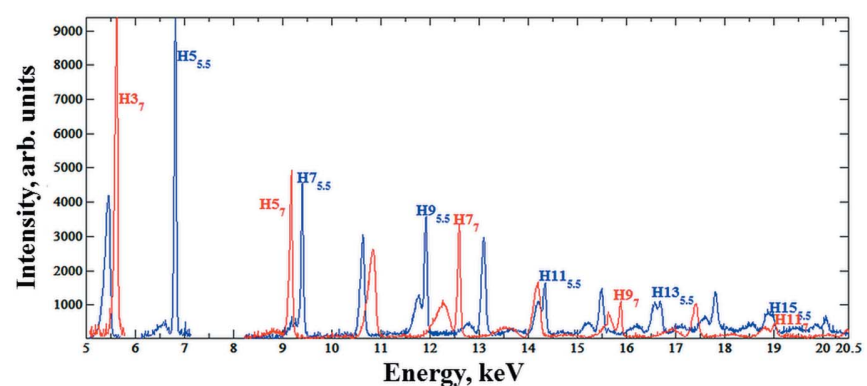

(a)

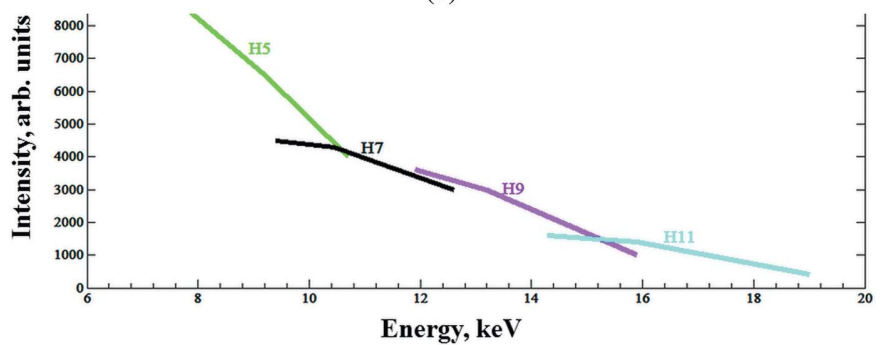

(b)

Figure 2

(a) Spectral distribution of the cryo-U18 undulator measured within a $1.3 \mu \mathrm{rad}$ emission cone-angle at $5.5 \mathrm{~mm}$ (in blue) and $7 \mathrm{~mm}$ (in red) gaps. (b) Measured relative flux of the fifth to 11th undulator harmonics in the $5.5-8 \mathrm{~mm}$ undulator gap range.

the maximum total beam power to $91 \mathrm{~W}$ which corresponds to $142 \mathrm{~W} \mathrm{~mm}^{-2}$ power density.

Water-cooled chemical vapour deposition diamond (CVD) and Be filters can be introduced into the beam path in front of the mirrors in order to optimize the X-ray beam intensity and absorbed power depending on the beam energy. As an alternative, any combination of the CVD-based transparent X-ray beam imagers (Bordessoule, 2012) can be kept in the beam; each imager corresponds to an additional $400 \mu \mathrm{m}$ CVD thickness.

\subsection{Pre-focusing mirrors}

The optical design of the beamline aims to create a highstability nanobeam by the all horizontally reflecting main beamline optics (mirrors, monochromators) and by the overfilled secondary source (SS) (Fig. 3). Each of the M1 and the M2 fixed curvature mirrors (WinlightX, France) deflects the beam by $5 \mathrm{mrad}$ in the outboard direction. The mirror orientation can be adjusted by independent motorized displacements (provided by ISP System, France). The Rh coating of the M1 vertically focusing mirror and the Si- and Rh-coated stripes of the M2 horizontally focusing mirror ensure the higher-order harmonics rejection over the whole 5-20 keV energy range. The two consecutive mirrors reduce the total power on the beamline elements that follow to $\leq 46 \mathrm{~W}$ ( $\mathrm{Si}$ stripe of M2) or $\leq 60 \mathrm{~W}$ (Rh stripe of M2), respectively. Due to the small $\left(\leq 50 \mathrm{~mW} \mathrm{m^{-2 }}\right)$ power density absorbed by each mirror, water cooling is sufficient for their temperature control.

The use of independent mirrors ensures independent focusing in the horizontal and vertical directions, and easy alignment of the beamline. Moreover, flexible beamline operation and feedback can be ensured without significant degradation of the beam quality.

The $\sigma_{\mathrm{SSh} / \mathrm{v}}$ size of the X-ray beam at the SS position depends on the magnified source size $\left(S_{\mathrm{SSh} / \mathrm{v}} \times q_{1 \mathrm{~h} / \mathrm{v}} / p_{1 \mathrm{~h} / \mathrm{v}}\right)$, the contribution of the optical quality of the mirrors $\left(\sigma_{\mathrm{opt}}\right)$ and the blurring due to eventual vibration $\left(\sigma_{\text {vibr }}\right)$,

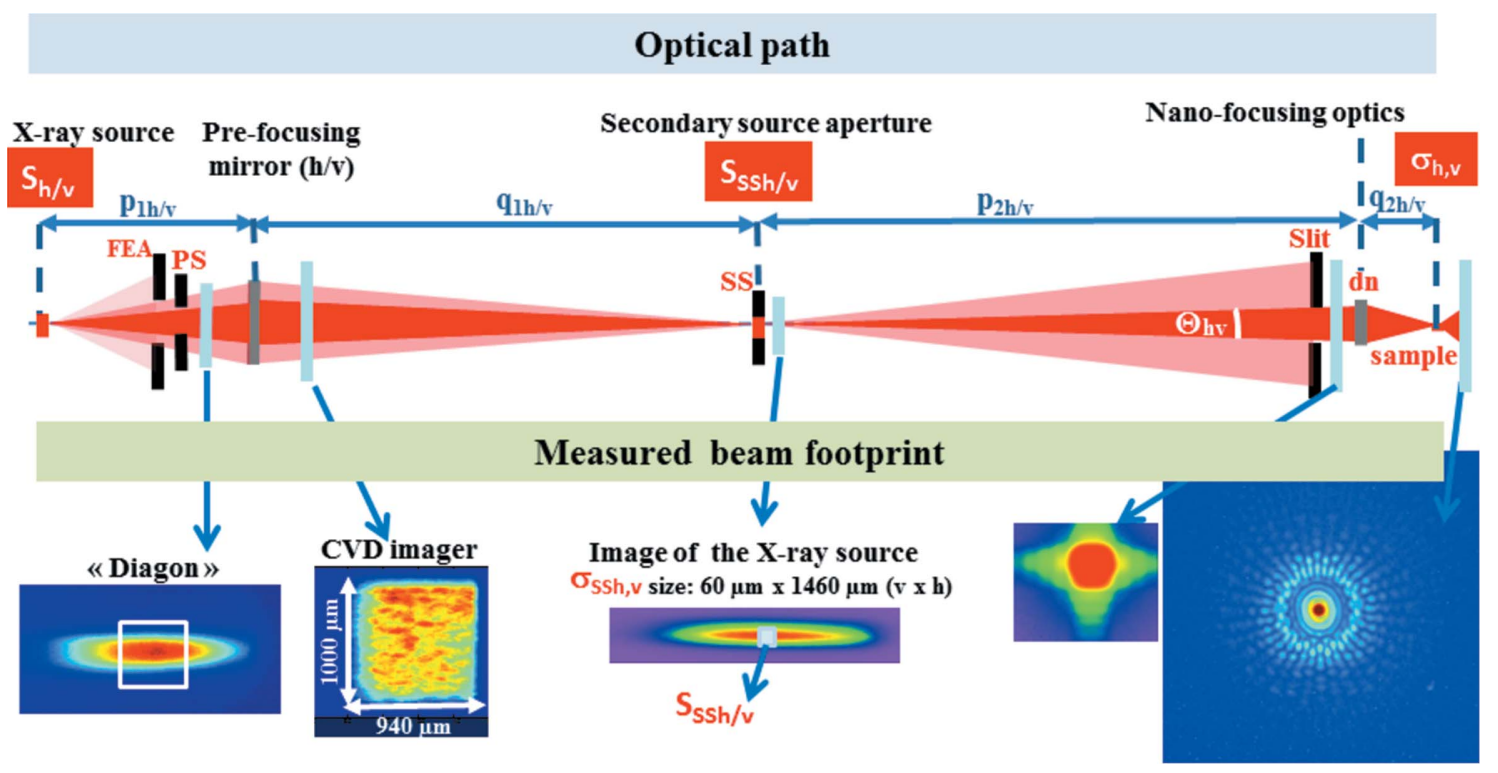

Figure 3

Top: vertical/horizontal optical beam path (not to scale). $S_{\mathrm{h} / \mathrm{v}}$ is the size of the X-ray source, $\sigma_{\mathrm{SSh} / \mathrm{v}}$ is the size of the beam at the SS position, $S_{\mathrm{SSh} / \mathrm{v}}$ is the size of the SS aperture and $\sigma_{\mathrm{h} / \mathrm{v}}$ is the size of the focused nanobeam. $p_{1 \mathrm{~h} / \mathrm{v}}$ and $q_{1 \mathrm{~h} / \mathrm{v}}$ are the source-to-prefocusing-mirror and mirror-to-SS distances, respectively, $p_{2 \mathrm{~h} / \mathrm{v}}$ is the source distance, $q_{2 \mathrm{~h} / \mathrm{v}}$ is the image distance and $d n$ is the optical aperture of the nano-focusing optics. Bottom: beam footprint captured by the imagers along the beam path. The white rectangle on the Diagon shows the size of the front-end aperture, and the light-blue rectangle positioned at the SS image represents a typical secondary source size. The last image shows a coherent diffraction pattern of a Siemens star. 


$$
\sigma_{\mathrm{SSh} / \mathrm{v}} \approx\left[\left(S_{\mathrm{h} / \mathrm{v}} \frac{q_{1 \mathrm{~h} / \mathrm{v}}}{p_{1 \mathrm{~h} / \mathrm{v}}}\right)^{2}+\sigma_{\mathrm{opt}}^{2}+\sigma_{\mathrm{vibr}}^{2}\right]^{1 / 2} .
$$

The $q_{1 \mathrm{~h} / \mathrm{v}}$ image distance, and as such the $\sigma_{\mathrm{SSh} / \mathrm{v}}$ beam size, depends on the $\rho_{\text {sag }}, \rho_{\text {tan }}$ effective sagittal and tangential radius of curvature of the M1-M2 mirror pair having $\Theta_{\mathrm{M} 1}$, $\Theta_{\mathrm{M} 2}$ incidence angles and $f_{1 \mathrm{v}}, f_{1 \mathrm{~h}}$ focal distances,

$$
f_{1 \mathrm{v}}=\frac{\rho_{\mathrm{sag}}}{2 \sin \Theta_{\mathrm{M} 1}}, f_{1 \mathrm{~h}}=\frac{\rho_{\mathrm{tan}} \sin \Theta_{\mathrm{M} 2}}{2}, q_{1 h / v}=\frac{f_{1 \mathrm{~h} / \mathrm{v}} p_{1 \mathrm{~h} / \mathrm{v}}}{p_{1 \mathrm{~h} / \mathrm{v}}-f_{1 \mathrm{~h} / \mathrm{v}}} \text {. }
$$

The sagittal radius of curvature of M1 measured in the Soleil Metrology Laboratory is $\rho_{\text {sag, } \mathrm{M} 1}=81.7 \mathrm{~mm}$ matching within $0.2 \%$ of the $81.5 \mathrm{~mm}$ nominal value. The $\rho_{\text {tan, } \mathrm{M} 1}=89.5 \mathrm{~km}$ tangential slope error of M1 obtained by post-delivery metrology was taken into account for determining the nominal $\rho_{\mathrm{tan}, \mathrm{M} 2}$ of M2. The measured $\rho_{\mathrm{tan}, \mathrm{M} 2}=21.4 \mathrm{~km}$ (Soleil Metrology Laboratory) provides an effective $\rho_{\tan }=17.3 \mathrm{~km}$ slope error of the M1 + M2 mirror pair.

The $\sigma_{\mathrm{opt}}$ contributions, $0.34 \mu \mathrm{rad}$ (r.m.s.) for M1, $0.3 \mu \mathrm{rad}$ for the Rh stripe and $0.39 \mu \mathrm{rad}$ for the Si stripe of M2, were estimated from the measured tangential slope errors by Monte Carlo simulation (Moreno \& Idir, 2001) and correspond to $<10 \%$ horizontal beam size increase. The eventual vibration of the mirrors would result in the blurring of the secondary source. This is minimized by high-stability mirror positioning mechanics and by switching the motors off during operation conditions. Thus the theoretical vertical and horizontal beam size $S_{\mathrm{h} / \mathrm{v}} \times q_{1 \mathrm{~h} / \mathrm{v}} / p_{1 \mathrm{~h} / \mathrm{v}}$ at the SS position can be estimated as $60 \mu \mathrm{m} \times 1460 \mu \mathrm{m}$ (FWHM).

Dedicated X-ray imagers and X-ray beam position monitors (XBPMs) (Desjardins et al., 2007, 2014) developed at Soleil monitor the stability of the X-ray beam after each main beamline optics. The two white-beam XBPMs situated $60 \mathrm{~m}$ from each other behind the two mirrors ensure the angular beam monitoring with $\sim 20$ nrad sensitivity, which can be used for active angular feedback.

\subsection{Double-crystal fixed-exit $\mathrm{Si}(111)$ monochromator}

The $\mathrm{Si}(111)$ double-crystal fixed-exit monochromator (DCM; purchased from CINEL) works in horizontally reflecting geometry. The motor adjusting the main $\Theta_{\text {Bragg }}$ angle has $0.03 \mu \mathrm{rad}$ angular resolution and $2 \mu \mathrm{rad}$ accuracy over any $0.2^{\circ}$ interval. The two degrees of freedom of the first crystal, which is equipped with direct cryo-cooling, permits the roll and the horizontal beam interception position to be adjusted. The horizontal translation also permits the first crystal to be removed from the beam in order to use a doublemultilayer monochromator (DMM). The second crystal is cryo-cooled by copper braids. It has five degrees of freedom: coarse pitch with a stepper motor, piezo-motor-based fine pitch, yaw, roll and horizontal translation; the last two ensure the fixed-exit operation. The eventual vibrational instabilities are monitored by an accelerometer installed at the support of the first crystal. A multilayer monochromator will be installed in the near future for obtaining increased flux with reduced spectral resolution. Both monochromators are situated in front of the secondary source. These two interchangeable monochromators will ensure the trade-off between high energy resolution $\left(\Delta E / E \simeq 10^{-4}\right)$ and high nano-beam flux $\left(10^{11}\right.$ photons $\mathrm{s}^{-1}$ with $\left.\Delta E / E \simeq 10^{-2}\right)$ depending on the experimental requirements.

A too high thermal load on the DCM will degrade the beam quality (wavefront and flux) and stability (thermal drift). The thermal deformation of the first Si crystal depends on the incident power, the power density and the beam footprint (Chumakov et al., 2014; Zhang et al., 2013). In spite of the relatively moderate total absorbed power, the first crystal is exposed to high power densities due to its position just in front of the secondary source, which results in $\sim 65-70 \mu \mathrm{m}$ (FWHM) vertical beam size. The horizontal beam footprint varies between 3 and $12 \mathrm{~mm}$ (FWHM) corresponding to the 23.4$5.7^{\circ}$ Bragg angle range. In spite of the moderate $\sim 46 \mathrm{~W}$ maximum absorbed power, the $155 \mathrm{~W} \mathrm{~mm}^{-2}$ highest power density of the first crystal necessitates cryogenic cooling (Huang et al., 2014; Zhang et al., 2013). A power slit positioned upstream of the DCM can be used to reduce the total heatload in order to optimize the performance in the whole absorbed heat-load range. The total power and power density can also be efficiently reduced with minimal intensity loss in the whole energy range by inserting beamline heat-load filters.

\subsection{Secondary source}

The design goal of Nanoscopium is to minimize the effect of the instabilities of the source and the optical elements by creating an overfilled secondary source (spatial filtering). The SS is situated at $81.6 \mathrm{~m}$ from the undulator source behind the main optical elements. As such, any beam vibration or drift caused by the beamline optics induces intensity change after the SS, but no virtual source motion. The size of the secondary source, $S_{\mathrm{SS}}$, is defined by a water-cooled high-precision custom-designed slit-pair developed at Soleil (Ribbens et al., 2013). The slit opening can be adjusted in both directions in the $0-1.5 \mathrm{~mm}$ range with $<100 \mathrm{~nm}$ resolution by symmetrical displacement of the two blades. The slit translation is controlled by independent motors, which permit $<500 \mathrm{~nm}$ positioning precision in the $\pm 3 \mathrm{~mm}$ range. The travel range of the horizontal slit position is $30 \mathrm{~mm}$. The polished blades are made from tungsten ( $\geq 98 \%$ ) of $2 \mathrm{~mm}$ thickness. Each blade has a wedge shape with $2^{\circ}$ slope to the incoming beam. Moreover, the eventual parasitic scattering is filtered by additional guard slits installed at the entrance of the experimental hutches. Despite the low, $<1 \mathrm{~mW}$, monochromatic heat-load impinging onto the SS, its temperature is controlled by low-debit water cooling. The $\sim 0.5 \mathrm{~W}$ maximum power of the future DMM can also be handled by water cooling. An imager, an intensity monitor and an XBPM are mounted downstream of the SS to monitor the monochromatic beam intensity and the beam position variation with $0.1-1 \mu \mathrm{m}$ r.m.s. spatial resolution. With these monitoring devices we have not detected so far any significant measurable instability in the opening size and position of the SS. 
The SS permits the beamline performance to be optimized for multimodal operation by adapting the beam size, flux and the beam coherence to the experimental needs. We use the phase-space parameter, $p=S_{\mathrm{SS}} \Theta / \lambda$ (Winn et al., 2000), for quantifying the spatial coherence, where $\Theta_{\mathrm{h} / \mathrm{v}}=d n / p_{2 \mathrm{~h} / \mathrm{v}}$ is the full angular acceptance of the nano-focusing optics (see Fig. 3) and $\lambda$ is the wavelength of the X-rays. In the $p \leq 0.5$ phasespace area, high spatial resolution can be obtained, whereas by varying $p=0.5$ to $p=1$ the near diffraction-limited spatial resolution is reduced by $\sim 20 \%$ while gaining $\sim 200 \%$ flux. At Nanoscopium in the 5-20 keV range this can be achieved by adjusting the $S_{\mathrm{SS}}$ slit size in the $60-15 \mu \mathrm{m}$ range if we use a nano-focusing optic of $300 \mu \mathrm{m}$ aperture situated at $70 \mathrm{~m}$ from the SS. The beam divergence after the SS assures that the focusing optics is comfortably overfilled, which leads to loss of coherent flux, but improves the stability and uniformity of illumination.

\subsection{Nanofocusing optics and spectro-microscopy stations}

The consecutive, complementary chromatic [Fresnel zone plate (FZP)] and achromatic [Kirkpatrick-Baez (KB)] spectro-microscopy stations are situated in the second experimental hutch (EH2). These ensure the optimization of the experimental conditions in the function of the energy bandwidth, demanded flux, nano-beam size, coherence characteristics and the desired energy tunability of the actual experiment. Both set-ups aim to reach near diffraction-limited focusing for high-spatial-resolution experiments.

The effective size of the focused nano-beam can be written as

$$
\sigma_{\mathrm{h} / \mathrm{v}} \approx\left(\sigma_{\mathrm{DLh} / \mathrm{DLv}}^{2}+\sigma_{\mathrm{DMh}, \mathrm{v}}^{2}+\sigma_{\mathrm{opt}}^{2}+\sigma_{\mathrm{stab}}^{2}\right)^{1 / 2}
$$

where $\sigma_{\mathrm{DLh} / \mathrm{DLv}}$ is the diffraction-limited horizontal and vertical beam size, $\sigma_{\mathrm{DMh}, \mathrm{v}}=S_{\mathrm{SSh} / \mathrm{SSv}} \times\left(q_{2 \mathrm{~h} / 2 \mathrm{v}} / p_{2 \mathrm{~h} / 2 \mathrm{v}}\right)$ is the contribution of the de-magnified SS, $\sigma_{\text {opt }}$ is the contribution due to the imperfect optical quality of the focusing optics (e.g. mirror figure error) and $\sigma_{\text {stab }}$ is the eventual beam size blurring due to overall instability effects. The diffraction-limited beam size is usually expressed by the Rayleigh resolution as $\sigma_{\mathrm{DL}}=0.61 \lambda / \mathrm{NA}$, where NA is the numerical aperture of the optic. In order to reach diffraction-limited focusing, the contributions of $\sigma_{\mathrm{DM}}, \sigma_{\mathrm{opt}}$ and $\sigma_{\text {stab }}$ must be negligible.

Dedicated FZP lenses, to be used in the $5-15 \mathrm{keV}$ energy range to reach down to $30 \mathrm{~nm}$ focused beam size (Mohacsi et al., 2014, 2015), are in construction in collaboration with the Laboratory for Micro- and Nanotechnology of PSI (headed by C. David). The achromatic total reflection nano-focusing KB mirror-pair (the mirrors are provided by JTEC and the positioning mechanics by Bruker) (Siewert et al., 2012; Mimura et al., 2005) are situated at $p_{2 \mathrm{~h} / \mathrm{v}} \simeq 71 \mathrm{~m}$ distance from the secondary source. The optically useful mirror lengths $(L)$ of the elliptically shaped mirrors are $92 \mathrm{~mm}$. The image distances and the average incidence angles of the vertically and horizontally focusing mirrors are $q_{2 \mathrm{v}}=0.285 \mathrm{~m}, q_{2 \mathrm{~h}}=0.18 \mathrm{~m}$ and $\Theta_{\text {inc,v }}=3 \mathrm{mrad}, \Theta_{\text {inc,h }}=2.5 \mathrm{mrad}$, respectively. The smallest diffraction-limited beam size, which can be obtained at $20 \mathrm{keV}$, is $\sigma_{\mathrm{DL}, \mathrm{v}} \times \sigma_{\mathrm{DL}, \mathrm{h}}=65 \mathrm{~nm} \times 48 \mathrm{~nm}(\mathrm{FWHM})$.

The demagnification of the secondary source of $S_{\mathrm{SS}, \mathrm{h}} \times S_{\mathrm{SS}, \mathrm{v}}$ $=10 \mu \mathrm{m} \times 10 \mu \mathrm{m}$ size (also ensuring at $20 \mathrm{keV}$ the coherent illumination of the $\mathrm{KB}$ for diffraction-limited focusing with $p_{\mathrm{v}}=0.7$ and $\left.p_{\mathrm{h}}=0.6\right)$ gives $\sigma_{\mathrm{DM}, \mathrm{v}}=41 \mathrm{~nm}\left(M_{\mathrm{v}}=0.0041\right)$ and $\sigma_{\mathrm{DM}, \mathrm{h}}=26 \mathrm{~nm}\left(M_{\mathrm{h}}=0.0026\right)$ and as such slightly increases the overall beam size to $\sigma_{\mathrm{DL}, \mathrm{v}} \times \sigma_{\mathrm{DL}, \mathrm{h}}=76 \mathrm{~nm} \times 55 \mathrm{~nm}$. The measured optical quality of the JTEC mirrors assures no significant beam blurring (Kewish et al., 2013).

Fast-scanning multi-technique imaging (Medjoubi et al., 2013) is implemented at the spectro-microscopy stations and provides access to $2 \mathrm{D} / 3 \mathrm{D}$ information on the sample morphology (absorption, differential phase contrast and dark field) together with the elemental distribution. The future implementation of cryo-cooling at the KB-based station will reduce the radiation damage of sensitive samples during the measurements. A sample stage equipped with cryo-cooling (Meents et al., 2013) is under development in the framework of collaboration with the P11 beamline of DESY (Hamburg, Germany).

\section{Beamline performance}

\subsection{Prefocusing mirrors}

The M1 and M2 mirrors focus the X-ray source at the position of the secondary source. The pitch angles of both M1 and M2, and the yaw of M1 have a significant effect on the quality of the focused beam. The variation of the pitch and yaw angles of M1 impacts the vertical beam size and beam shape, whereas the pitch of M2 affects the horizontal beam size. As such, the horizontal and vertical beam sizes and beam quality can be optimized independently.

The smallest vertical beam size was determined by varying the $\Theta_{\mathrm{M} 1}$ incidence angle (pitch) of the sagittally focusing M1 mirror and was found to be $\sim 61 \mu \mathrm{m}$ (FWHM) without any significant change in the $\Delta \Theta_{\mathrm{M} 1}= \pm 10 \mu \mathrm{rad}$ pitch range (Fig. $4 a$ ). The effect of the yaw of M1 on the vertical beam size and beam orientation can be seen in Fig. 4(b). The variation of the yaw of M1 does not cause either significant beam size increase or beam-shape distortion in the $\pm 20 \mu \mathrm{rad}$ range. The measured smallest $1200 \mu \mathrm{m}$ (FWHM) horizontal beam size is determined by the effective optical lengths of M1 and M2. No significant horizontal beam size variation could be measured in the $\Delta \Theta_{\mathrm{M} 2}= \pm 10 \mu \mathrm{rad}$ range of the pitch of $\mathrm{M} 2$.

As such, using two independent mirrors for sagittal and tangential focusing ensures next to easy beamline alignment, the possibility of efficient and sensitive beam position feedback without beam-quality degradation. Thorough stability tests using the already installed intensity and beam-position monitors are in progress and will be the basis to establish a feedback strategy if necessary.

\subsection{Double-crystal fixed-exit Si(111) monochromator}

The characterization of the effect and severity of the thermal deformation of the crystal is a complex task. As a 


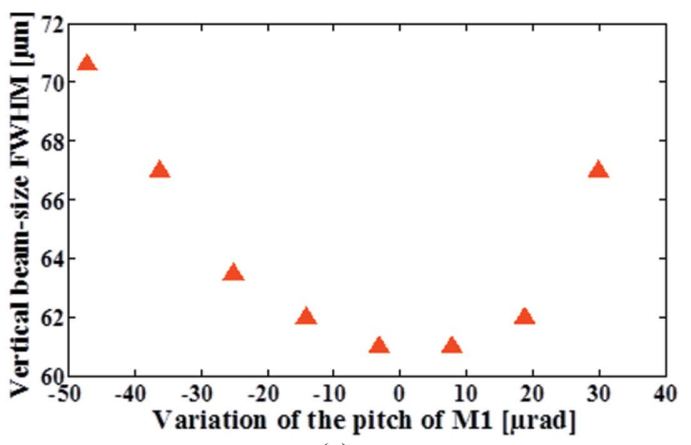

(a)

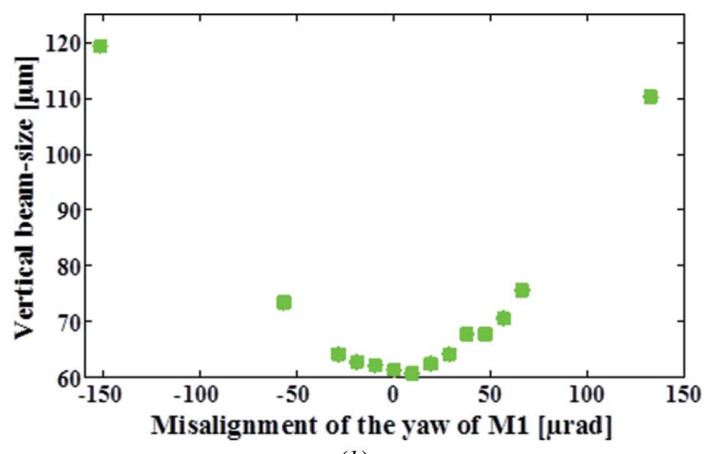

(b)

Figure 4

(a) Measured vertical beam size at the position of the secondary source (SS) as a function of the pitch of the sagittally focusing M1 mirror. The smallest measured vertical beam size is $\sim 61 \mu \mathrm{m}$ FWHM. (b) Variation of the vertical beam size as a function of the yaw of M1.

first step we calculated the $P_{\mathrm{M}}$ modified linear power density, as suggested by Huang et al. (2014), as $P_{\mathrm{M}}=$ $[1+\ln (L / W) / 2.57] P / L$, where $P$ is the total accepted power, and $L$ is the length and $W$ is the width of the X-ray footprint. This provides the possibility to estimate the severity of crystal thermal deformation independently of the beamline specifics. The obtained $P_{\mathrm{M}} \leq 35 \mathrm{~W} \mathrm{~m}^{-1}$ indicates that the crystal deformation remains in the linear region $\left(P_{\mathrm{M}}<50 \mathrm{~W} \mathrm{~m}^{-1}\right)$, where slope errors caused by thermal deformation increase linearly with heating power (Zhang et al., 2003). This might, next to wavefront distortion, increase the rocking-curve width and the vertical beam size at the secondary source position, which will result in loss of monochromatic flux.

The global effect of the thermal deformation of the first crystal of the DCM was investigated by measuring the rocking-curve broadening and the variation of the vertical beam size at the SS position at several energies in the full 5$20 \mathrm{keV}$ energy range. The total absorbed power and power density were varied by the filters and semi-transparent CVD imagers in front of the DCM. The measured rocking-curve broadening was $<0.1 \mu \mathrm{rad}$ in each condition, which is much smaller than the width of the Bragg reflection. Moreover, in good agreement with the negligible rocking-curve widening, no significant vertical beam size blurring has been detected at the SS position. These measurements confirm the good functioning of the cryo-cooled DCM.

In order to check the energy calibration stability of the DCM, several XANES spectra (Fig. 5) were collected around

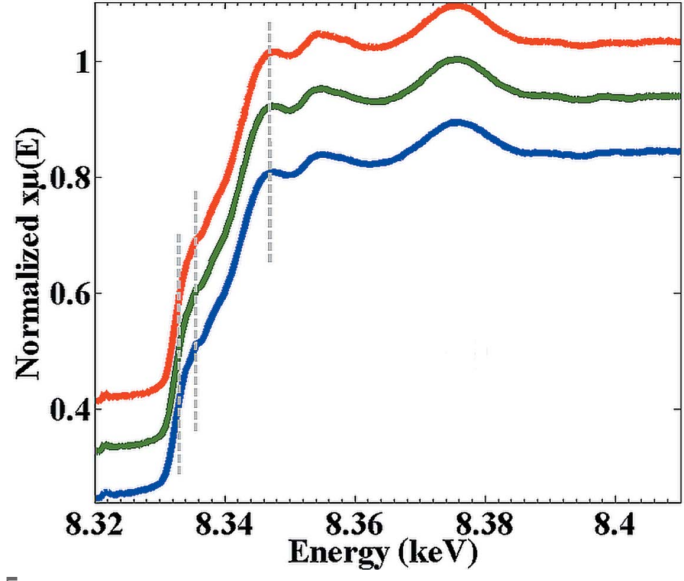

Figure 5

XANES spectra collected with $0.25 \mathrm{eV}$ steps around the $K$-edge of a standard Ni foil of $5 \mu \mathrm{m}$ thickness (EXAFS Materials, USA) during a $7 \mathrm{~h}$ period. The spectra are shifted vertically for clarity.

the $K$-edge of a standard Ni foil of $5 \mu \mathrm{m}$ thickness (EXAFS Materials, USA) during a $7 \mathrm{~h}$ period. The energy was calibrated by taking the maximum of the first derivative of the edge as $8.333 \mathrm{keV}$. The inflections points of the Ni $K$-edge XANES spectrum remained stable within $<0.25 \mathrm{eV}$ during this measurement period.

\subsection{Experimental stations}

The Nanoscopium beamline aims to provide multi-technique imaging and tomography at hierarchical length-scales during a typical user experiment in order to offer insight into the structural and elemental distribution of the samples with the possibility of performing a chemical speciation study. One of the most important requirements for such multi-lengthscale experiments is the possibility of performing fast and large field of view ( $\geq \mathrm{mm}^{2}$ ) scans, followed by zooming into chosen smaller $\left(\sim \mu \mathrm{m}^{2}\right)$ sample areas with high spatial resolution. The multi-technique flyscan developed at Soleil (Medjoubi et al., 2013) provides the software and hardware infrastructure for such hierarchical length-scale measurements.

3.3.1. Focusing characteristics of the KB mirror. In order to estimate the smallest spatial resolution achievable at the KBbased spectro-microscopy station, the size of the focused beam was measured by performing knife-edge scans at different SS slit openings at 16.7 and $8.4 \mathrm{keV}$ energies. The horizontal and vertical beam sizes of $75 \mathrm{~nm}$ (FWHM) and $100 \mathrm{~nm}$ (FWHM) measured with a step-scan at $20 \mu \mathrm{m} \times 20 \mu \mathrm{m}$ SS slit opening at $16.7 \mathrm{keV}$ can be seen in Figs. 6( $a)$ and 6(b). This beam size will determine the highest possible spatial resolution. However, in the case of continuous scanning measurements, the effective spatial resolution is 'blurred' by the motor movement, e.g. $100 \mu \mathrm{m} \mathrm{s}^{-1}$ motor speed with $10 \mathrm{~ms}$ dwell time means that the sample has been moved by a 'step' of $1 \mu \mathrm{m}$ while one detector frame is exposed and read out.

The intensity in the focused beam was measured by a $300 \mu \mathrm{m}$-thick Si photodiode (see Table 2). During all the 
measurements, preliminary He-filled tubes were introduced into the beam path in order to decrease the absorption of air. The measurements were performed with the $700 \mu \mathrm{m}$-thick Be filter introduced into the beam path. The entrance window of $\mathrm{EH} 2$ and the $\mathrm{Be}$ windows of the $\mathrm{KB}$ represent an additional total $450 \mu \mathrm{m}$ Be thickness. The measured flux is in good agreement with the estimated one at $16.7 \mathrm{keV}$ energy. At $8.4 \mathrm{keV}$, the difference between the measured and estimated flux is likely to originate from the remaining air-path, which will be optimized as part of the finalization of the set-up. The diffraction pattern of a gold grating nanostructure having a period of $300 \mathrm{~nm}$ was registered at an SS slit opening of $20 \mu \mathrm{m}$ $\times 20 \mu \mathrm{m}$ at $2.5 \mathrm{~m}$ behind the sample at $8.4 \mathrm{keV}$ energy with the XPAD detector (Fig. $6 c$ ). The large number of visible fringes shows the high degree of coherence of the focused beam and the excellent optical quality of the KB.

The flexible beamline design makes it straightforward to adapt the beam size, beam-coherence characteristics and the beam intensity according to the requirements of the experiment without any beamline realignment only by tailoring the SS slit opening.

3.3.2. Multi-technique hierarchical length-scale experiments. The goal of hierarchical length-scale multi-technique imaging is to make possible dynamical zooming into the chosen region of a sample. As such, the study of the interaction between different length-scale features is becoming possible together with the identification of rare nano-sized features in bulk samples. Several main application fields of the beamline, amongst others geology, paleo-geobiology, earthand environmental sciences, where the samples of study are heterogeneous at different length-scales containing major, minor and trace elements, will highly benefit from such multitechnique and multi-length-scale imaging possibilities. The regions of interest for high-resolution and high analytical sensitivity measurements are to be identified from coarse, large field of view fast imaging, which ideally is performed in $\leq 1 \mathrm{~h}$. This makes it possible to identify the interesting sample
Table 2

Measured size and intensity of the focused beam by the JTEC KB mirror at different secondary slits apertures.

The intensity in the nano-beam was measured by a $300 \mu \mathrm{m}$-thick Si diode. The calculated intensity takes into account the $\sim 1 \mathrm{~m}$ air-path and $1.15 \mathrm{~mm} \mathrm{Be}$ thickness, which was introduced into the beam path during the measurements.

\begin{tabular}{lllll}
\hline & & $\begin{array}{l}\text { Measured focused } \\
\text { beam size }\end{array}$ & $\begin{array}{l}\text { Intensity in the focused beam } \\
\left(\text { photons s }^{-1}\right)\end{array}$ \\
\cline { 4 - 5 }$(\mathrm{keV})$ & $\begin{array}{l}\text { SS slit size } \\
\mathrm{H} \times \mathrm{V}(\mu \mathrm{m})\end{array}$ & $\mathrm{H} \times \mathrm{V}(\mathrm{nm})$ & Measured & Calculated \\
\hline 8.4 & $50 \times 50$ & $180 \times 225$ & $3.2 \times 10^{9}$ & $5.6 \times 10^{9}$ \\
& $20 \times 20$ & $130 \times 170$ & $3.6 \times 10^{8}$ & $9.1 \times 10^{8}$ \\
16.7 & $50 \times 50$ & $120 \times 180$ & $3.5 \times 10^{9}$ & $4.9 \times 10^{9}$ \\
& $50 \times 20$ & $120 \times 100$ & $1.4 \times 10^{9}$ & $2 \times 10^{9}$ \\
& $20 \times 20$ & $75 \times 100$ & $6.3 \times 10^{8}$ & $7.8 \times 10^{8}$ \\
\hline
\end{tabular}

features from relevant characteristics (e.g. metal content and distribution, scattering features, internal sample morphology), which are not observable by optical microscopy or by other laboratory methods.

In order to characterize the multi-length-scale and multitechnique analytical possibilities for geological applications, a representative $80 \mu \mathrm{m}$-thick, polished thin section of an Archeaen rock sample was investigated (see visible microscope image in Fig. 7) at $16.7 \mathrm{keV}$ incident beam energy. The beam size during these measurements, performed with $\mathrm{H} \times \mathrm{V}=50 \mu \mathrm{m} \times 20 \mu \mathrm{m}$ SS slit opening, was $120 \mathrm{~nm} \times$ $100 \mathrm{~nm}$ FWHM (see Table 2 and Fig. 6). The flat rock sample was positioned perpendicularly to the incoming beam in order to preserve the small beam footprint at the sample.

$\mathrm{X}$-ray fluorescence (XRF) spectra were recorded at each pixel by two silicon drift detectors of $50 \mathrm{~mm}^{2}$ useful area (KETEK H50, KETEK GmbH) used with XMAP (XIA LLC) fast digital multichannel analyser cards. The detectors were placed at a $\sim 20^{\circ}$ angle symmetrical to the sample surface. The elemental distribution maps (see $\mathrm{As}, \mathrm{Fe}, \mathrm{V}$ and $\mathrm{Zn}$ in Fig. 7) were reconstructed from the full XRF spectrum measured in each pixel by using preselected spectral regions of interest (ROIs) and summing the intensities measured by the two detectors. The transmitted beam was recorded either by a fast XPAD pixel detector containing $120 \times 560$ pixels of $130 \mu \mathrm{m}$ pixel size (Medjoubi et al., 2010) or by a $300 \mu \mathrm{m}$-thick diode. Encoded positions of the sample positioning stages were recorded at each scan step.

As a first step, large field of view $(\mathrm{H} \times \mathrm{V}=716 \mu \mathrm{m} \times 500 \mu \mathrm{m})$ moderate-resolution $\quad(\sim 1 \mu \mathrm{m} \quad \times$ $1 \mu \mathrm{m})$ 2D elemental distribution and transmission contrast maps (with the $\mathrm{Si}$ diode) were measured with $100 \mu \mathrm{m} \mathrm{s}^{-1}$ horizontal scanning speed, $10 \mathrm{~ms}$ per point dwell time and $1 \mu \mathrm{m}$ vertical steps in a total measurement time of $\sim 1 \mathrm{~h}$. Because at $50 \mu \mathrm{m} \times 20 \mu \mathrm{m}$ SS slit size the
Figure 6

Horizontal (a) and vertical (b) knife-edge scan measurements with the JTEC KB set-up at $16.7 \mathrm{keV}$ energy and $20 \mu \mathrm{m} \times 20 \mu \mathrm{m}$ SS slit opening. The $\sigma$ standard deviation and the correlation coefficient $(R)$ of the Gaussian fit of the first derivative, and the step-size are given. (c) Diffraction pattern (on logarithmic intensity scale) of a gold grating nanostructure measured with the XPAD pixel detector at $8.4 \mathrm{keV}$ with a $20 \mu \mathrm{m} \times 20 \mu \mathrm{m}$ SS slit opening at $2.5 \mathrm{~m}$ behind the sample. 

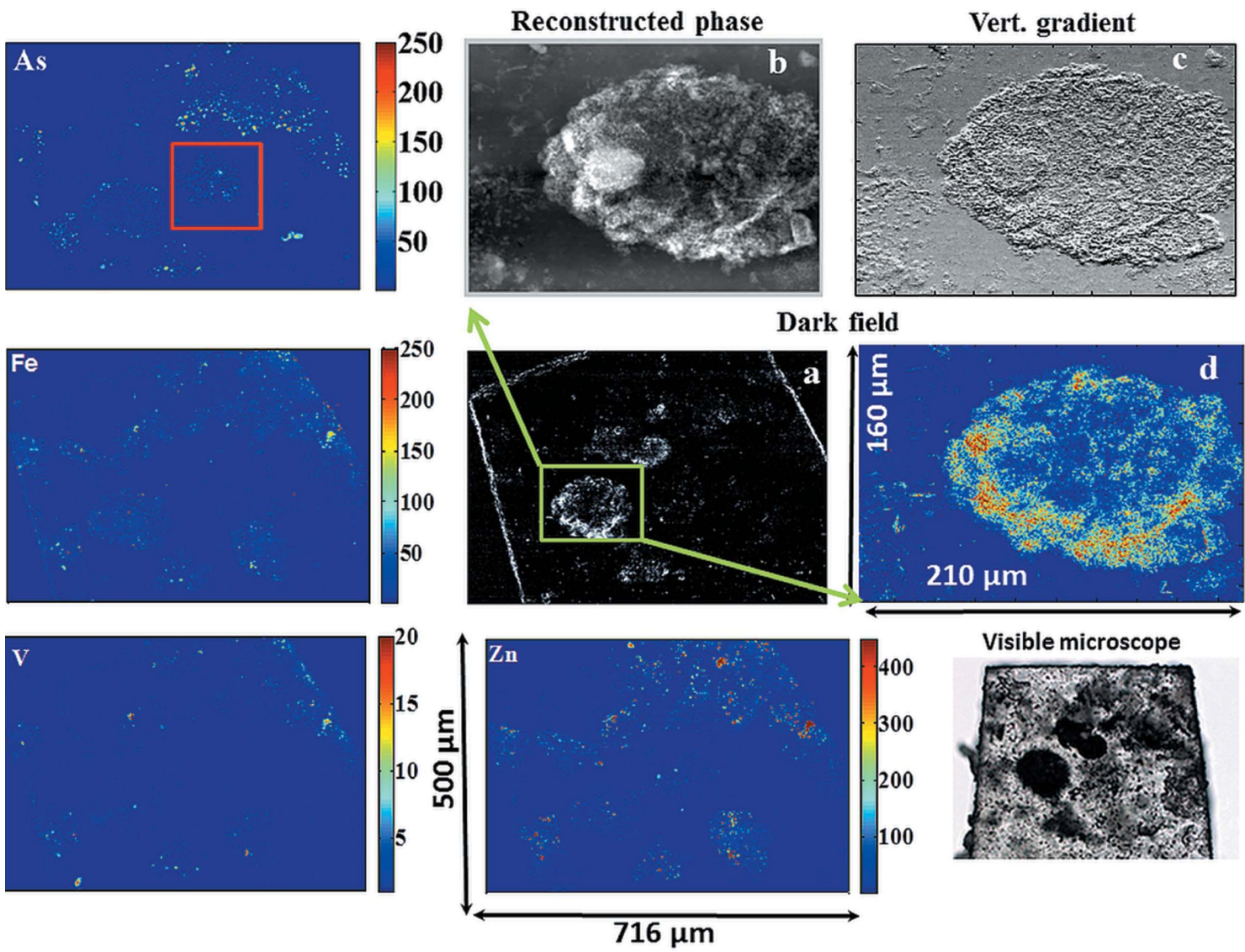

Figure 7

Reconstructed multimodal contrast modes of the measured Archeaen rock sample. The As, Fe, V and Zn distributions were obtained by scanning XRF. The coarse $(a)$ and higher-resolution $(d)$ dark-field distribution, the vertical gradient phase image $(c)$ and the reconstructed phase distribution (b) were calculated from the transmission images registered by the XPAD detector.

transmitted flux saturated the photon-counting XPAD pixel detector, the absorption-, differential phase- and dark-field (Fig. 7a) contrast maps were measured sequentially with a $5 \mu \mathrm{m} \times 5 \mu \mathrm{m}$ SS slit opening with a $3 \mathrm{~ms}$ dwell time per pixel (limited by the $1.5 \mathrm{~ms}$ read-out time of the XPAD) in an additional $20 \mathrm{~min}$. Metals such as $\mathrm{V}, \mathrm{Zn}$, As and Fe (see Fig. 7) and $\mathrm{Cr}, \mathrm{Ti}$ and $\mathrm{Ni}$ (not shown due to spatial limitations) show highly heterogeneous spatial distribution. Due to the high 250-400 counts per $10 \mathrm{~ms}$ intensity of the $\mathrm{Zn}, \mathrm{Fe}$ and As XRF signals, these measurements are feasible even at $1 \mathrm{~ms}$ per point dwell time, to the detriment of the detection of lowerconcentration elements Ti and Ni. Thus, coarse, large field of view scans revealing the major and minor element distribution could be completed in a total measurement time of some minutes. The dark-field contrast (Fig. 7a) shows highly scattering sample areas corresponding to the dark zones in the visible-light microscope image.

These coarse maps provide the possibility of zooming in on sample areas for high-resolution and higher analytical sensitivity $2 \mathrm{D}$ projection imaging based on the contrast mechanism relevant to the studied scientific question. For example, the highly scattering globular structure of $202 \mu \mathrm{m}(\mathrm{H}) \times 160 \mu \mathrm{m}$ (V) dimensions, marked by the green rectangle in the coarse dark-field image in Fig. 7(a), was scanned at $70 \mu \mathrm{m} \mathrm{s}^{-1}$ scan- ning speed, $3 \mathrm{~ms}$ dwell time and $250 \mathrm{~nm}$ vertical steps (in $\sim 30$ min total measurement time) for obtaining morphological information at higher resolution. The vertical gradient phase image, the phase reconstructed by Fourier integration of the complex sum of the horizontal and vertical gradient phase images (Arnison et al., 2004; Kottler et al., 2007) and the darkfield image can be seen in Figs. $7(b)-7(d)$. They reveal fine $[\sim 230 \mathrm{~nm}(\mathrm{H}) \times 250 \mathrm{~nm}(\mathrm{~V})$ spatial resolution] morphological details of this globular formation, containing micrometre-sized crystalline structures embedded into the ensemble of submicrometre-sized grains.

The sample area marked with a red rectangle in the As distribution map of Fig. 7 contains As and some Zn, without detectable amounts of other metals with these measurement conditions. A $70.4 \mu \mathrm{m} \times 89.6 \mu \mathrm{m}$ area of this sample region was further analyzed by higher-resolution continuous scanning. The As distribution measured with $10 \mathrm{~ms}$ per pixel dwell time, $20 \mu \mathrm{m} \mathrm{s}^{-1}$ scanning speed and $200 \mathrm{~nm}$ vertical steps $(\sim 220 \mathrm{~nm} \times 200 \mathrm{~nm}$ spatial resolution and 29.3 min total measurement time) can be seen in Fig. $8(a)$. The dark field (DF) (Fig. $8 b$ ) and integrated phase (Fig. $8 c$ ) of the area indicated by the green rectangle in Fig. 8(a) shows complex morphological texture with small, $\sim 4-5 \mu \mathrm{m}$-diameter, formations. The DF, the integrated phase and the As distribution 

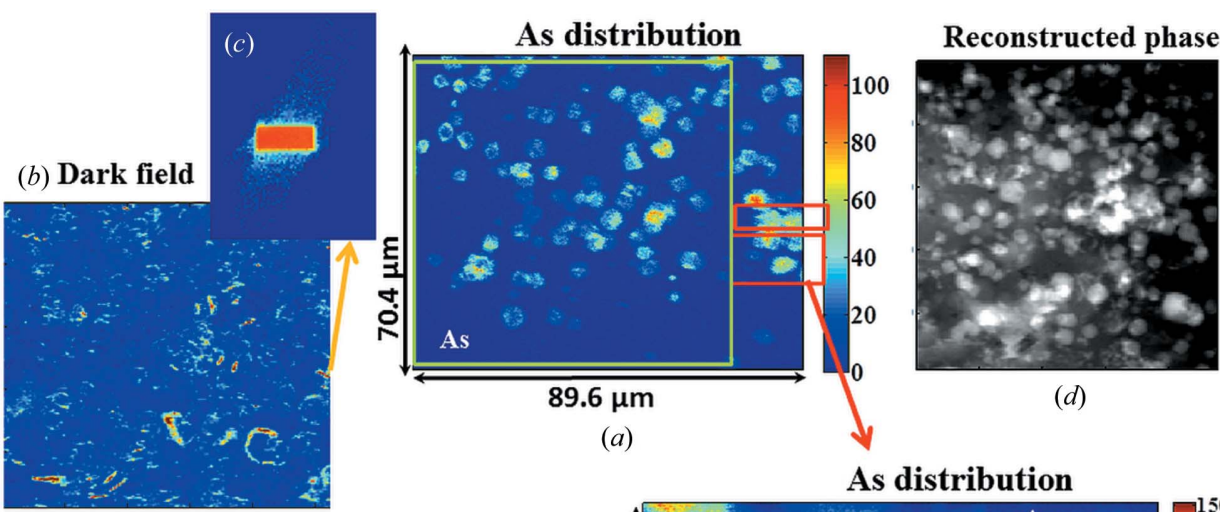

(d)

(a)

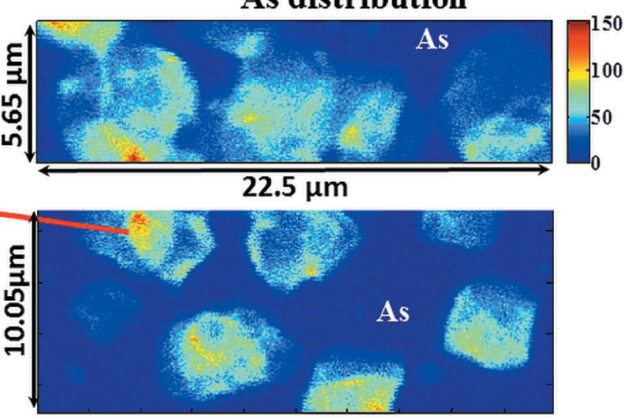

(e)

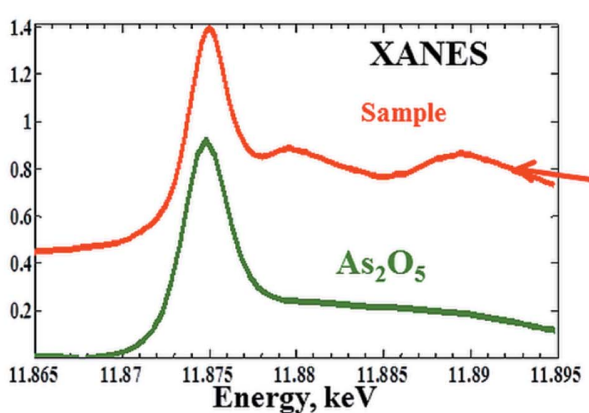

$(f)$

Figure 8

Multimodal images measured within the red rectangle indicated in the As distribution in Fig. 7. The dark field $(b)$ and reconstructed phase $(d)$ of the sample area within the green rectangle shown in the As distribution map (a) reveal complex sample morphology. (c) Coherent diffraction pattern in the sample spot marked by the orange arrow. The approximate highest $(130 \mathrm{~nm})$ resolution As distribution maps $(e)$ correspond to the red rectangles in $(a)$. $(f)$ XANES spectra measured around the As $K$-edge; red curve: at the indicated sample point; green curve: $\mathrm{As}_{2} \mathrm{O}_{5}$ standard. The XANES spectra of the sample and the $\mathrm{As}_{2} \mathrm{O}_{5}$ standard were shifted laterally for the clarity of the figure.

only partially correlate with each other, showing the complementarity of these contrast modes. The coherent scattering in the strongly scattering pixels shows strong angular orientation (see Fig. 8c), which follows the shape of the small globular features. This indicates that the scattering is originating from a surface layer of the small globules, which contains highly oriented $<220 \mathrm{~nm}$-sized structures, mostly oriented parallel to the surface layer. The detailed analysis of the DF images (e.g. Bunk et al., 2009) or the higher resolution psychographic reconstruction was not the aim of the present study and will be presented elsewhere. Clearly, the interpretation of such complex projection images would highly benefit from $3 \mathrm{D}$ measurements.

Slow, continuous XRF scans of the highest resolution $\left(5 \mu \mathrm{m} \mathrm{s}^{-1}\right.$ motor speed, $10 \mathrm{~ms}$ per pixel dwell time, $50 \mathrm{~nm}$ vertical steps and a $30 \mathrm{~min}$ total measurement time) were performed within the two sample areas marked by red rectangles in Fig. $8(a)$. They reveal the $\sim 130 \mathrm{~nm}$-scale inhomogeneous As distribution within the 4-5 $\mu \mathrm{m}$-diameter globules (Fig. 8e). Finally, a nano-XANES measurement was performed around the $K$-edge of $A s$ in the spot indicated in Fig. 8(e). The beam energy was calibrated by $\mathrm{As}_{2} \mathrm{O}_{5}$ and legrandite standards (only the $\mathrm{As}_{2} \mathrm{O}_{5}$ XANES is shown for the clarity of the figure). The XANES spectrum indicates the presence of $\mathrm{As}^{\mathrm{V}}$ in this As-rich sample spot (Fig. 8f).
As a next step, the internal structure and elemental distribution of the sample was studied by 3D tomography with moderate $\sim 2 \mu \mathrm{m} \times 2 \mu \mathrm{m}$ spatial resolution due to the rather large, $\sim 500 \mu \mathrm{m} \times$ $100 \mu \mathrm{m}$, dimensions of the sample slice. For these measurements both XRF detectors were oriented at $90^{\circ}$ to the incoming beam and the sample. This measurement geometry permits XRF tomography to be perfomed in only $180^{\circ}$ simultaneously with transmission and DF tomography, reducing the measurement time by $50 \%$, since $\mathrm{XRF}$ tomography is usually performed with one XRF detector in $360^{\circ}$. As a first step, fast 2D projection scans were performed at five different angles equally distributed over $180^{\circ}$. The five transmission and ten XRF projections have been obtained in less than $4 \mathrm{~h}$ ( $45 \mathrm{~min}$ per projection, with $200 \mu \mathrm{m} \mathrm{s}^{-1}$ motor speed and $10 \mathrm{~ms}$ per pixel dwell time).

A draft 3D reconstruction could be obtained from these projection scans ( $\mathrm{Hu}$ et al., 2014). The small number of angular projections limits the available spatial resolution of the $3 \mathrm{D}$ reconstruction (Kak \& Slaney, 1988). According to the sampling theorem, the total number of angular projections should be $n_{\varphi}=(\pi / 2) n_{\mathrm{R}}$ over $180^{\circ}$ for proper sampling, where $n_{\mathrm{R}}$ is the number of pixels per line scan. In spite of the aliasing artifacts in the reconstructed image, the draft $3 \mathrm{D}$ overview distribution of the absorption, dark field and major elements of the $1 \mathrm{~mm} \times$ $0.75 \mathrm{~mm} \times 0.08 \mathrm{~mm}$ sampled volume could be reconstructed using the unfiltered back-projection algorithm. The artifacts of the reconstructed tomograms were diminished by filtering out the high spatial frequencies and low-intensity signals. In Fig. 9(a), the volume rendering of the dark field (in grey) corresponding to high scattering, the transmission (grid) defining the sample volume and the Fe distribution (green) are shown. Fig. 9(b) shows a virtual slice, where spatially spread sample features and strong-contrast signals can be identified, which permits the sample area of interest to be chosen for a higher-resolution tomography experiment.

A $1000 \mu \mathrm{m} \times 750 \mu \mathrm{m} \times 40 \mu \mathrm{m}$ sample volume marked by the red rectangle in Fig. 9(a) and containing part of the large highly scattering globules was chosen on the basis of the coarse overview tomography for the moderate-resolution fast 3D tomographic scan. This was performed slice by slice with 250 angular projections per virtual slice. The 3D tomography measurement of the ten virtual slices took about $4 \mathrm{~h}$. The 

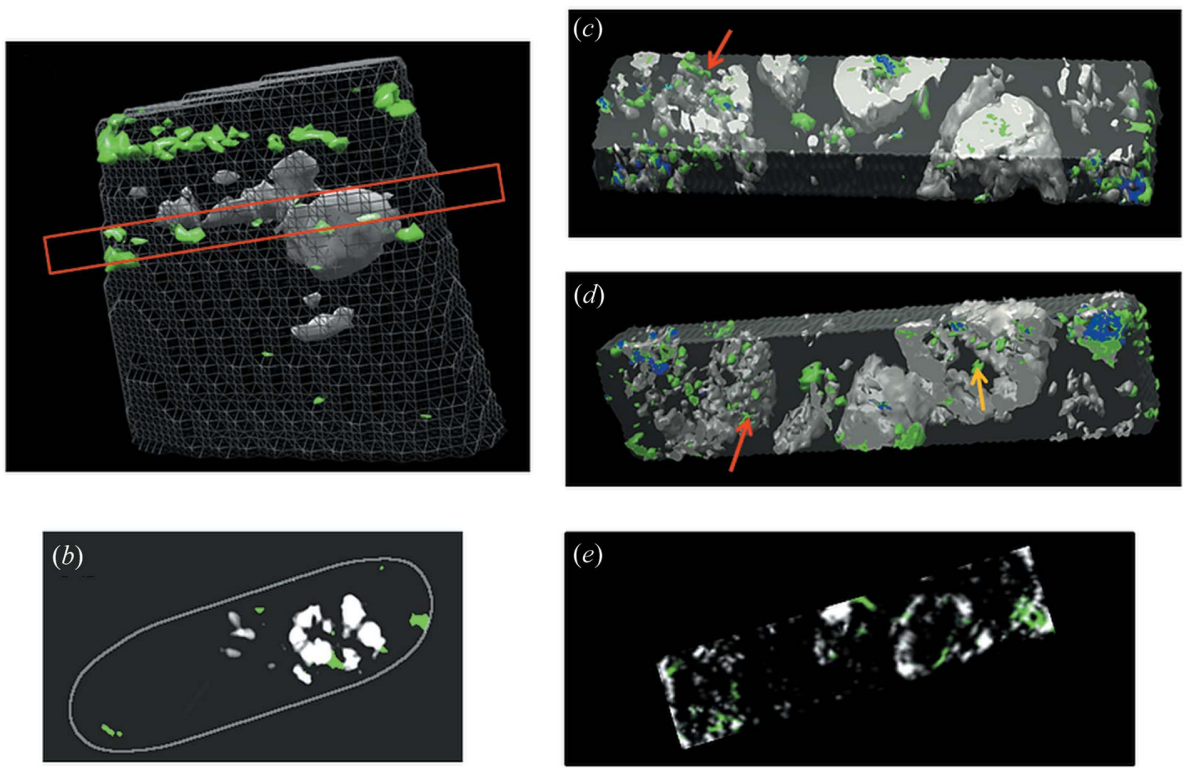

Figure 9

(a) Volume rendering of the coarse large field of view multi-technique overview tomography; the grid contains the sample contour obtained from absorption contrast, green indicates Fe and grey indicates the dark-field distribution. (b) A virtual slice obtained from the coarse tomographic reconstruction. $(c)$ Top view and $(d)$ bottom view of the volume rendering of the moderate $(\sim 2 \mu \mathrm{m})$ resolution scanning multi-technique tomography: the transparent area is absorption contrast, green indicates Fe, grey indicates the dark field and blue indicates the overlapping $\mathrm{Zn}$ and $\mathrm{Cr}$. (e) A virtual slice of the more detailed tomography obtained at the very same position as $(b)$.

nique and multi-length-scale possibility is one of the unique features of Nanoscopium that will permit studies to be performed which were only feasible until now by several successive measurements at different micro- and nanoprobe beamlines (Sforna et al., 2014). Such an operation mode dictates severe requirements on the fast-scanning sample-positioning stages, namely a large millimetre scanning range with $\leq 10 \%$ speed variation in a wide speed range (e.g. 1-500 $\left.\mu \mathrm{m} \mathrm{s}^{-1}\right)$, while keeping the sample positioning precision to some nanometres in slow scanning and step-scan modes. The characterization and optimization of the fast-scanning stages of Nanoscopium is in progress and aims to tackle these challenges.

The first test experiments showed that the analytical characteristics of the beamline are matching well the requirements of the typical geological and paleo-geological applications expected at the beamline. These test experiments demonstrated the feasibility of dwell times down to milli-

volume rendering of the absorption (transparent sample contour), dark field (grey), Fe (green) and the totally overlapping $\mathrm{Zn}$ and $\mathrm{Cr}$ (blue) distributions can be seen in a top view in Fig. 9(c) and in a bottom view in Fig. 9(d). Fig. 9(e) shows the very same virtual slice obtained with higher resolution than in Fig. 9(b). There is a good agreement between the shape of the large globular structures and the larger Fe grains in the draft and detailed tomographic reconstructions. Even the hollow structure of the large globule is revealed in Fig. 9(b). The more detailed micrometre spatial resolution 3D scan reveals additional internal structural and elemental details. For example, it permits two different elementalstructural associations to be identified: small, only $\mathrm{Fe}$ containing grains enclosed within the globular structures (yellow arrow), and $\mathrm{Zn}$-, $\mathrm{Cr}$ - and $\mathrm{Fe}-$ containing co-localized grains within larger highly absorbing grains (overlapping green and blue areas).

\section{Discussion}

The multi-technique scanning imaging option available at the spectro-microscopy stations of the Nanoscopium beamline offers the flexibility of choosing the beam characteristics (flux, beam size and coherence characteristics), scanning parameters and analytical methods to perform hierarchical length-scale imaging within a typical user experiment. As such, zooming dynamically between moderate micrometre-resolution scans of some $\mathrm{mm}^{2}$ large sample areas and $100 \mathrm{~nm}$ resolution of some $\mu \mathrm{m}^{2}$ sample areas is becoming available without the need for sample and beamline realignment. This multi-tech- seconds per pixel for coarse scans. The beamline design permits more flexibility than presented in the paper, namely the size of the focused beam can be matched by adapting the SS slit opening to the spatial resolution blurred due to the continuous motor displacement. As such, for coarse scans we could readily increase the flux impinging onto the sample by an order of magnitude (see, for example, Table 2). Thus, the same counting statistics as presented above could be achieved only in milliseconds per pixel dwell times. Moreover, the future DMM of the beamline will permit additional flux increase to the detriment of spectral resolution. However, these possibilities are restricted by the limited throughput of the recently available 2D detectors and XRF measurement chains. As a next step, the analytical performance of the beamline will be tested for biological applications. The special challenge of these applications is the detection of trace elements and weak transmission contrasts in radiation-sensitive fragile samples.

The large sample size and the figure of merit of performing 3D measurements in a total measurement time of some hours limited the spatial resolution of the presented tomography experiments. Sub-micrometric resolution XRF tomography is already feasible at Nanoscopium in the case of smaller samples. The development of local tomography would open up the possibility of hierarchical length-scale 3D measurements.

The high coherence of the focused beam (see Fig. 6c) can be exploited for ptychography experiments. This might be offered at the spectro-microscopy end-stations as a complementary technique to XRF, depending on the aim of the scientific study. 


\section{Conclusion and outlook}

The Nanoscopium scanning hard X-ray nanoprobe beamline is in the commissioning phase. It will complete the range of existing or forthcoming scanning nanoprobe beamlines at other synchrotrons. The first measured beamline performances show good agreement with the main design goals. The flexible optical design of the beamline ensures easy beamline alignment, which is an asset both for stability issues and for daily operation. The secondary source ensures the tailoring of the beam characteristics (coherence, beam size and flux at the sample) to the specific needs of the experiments.

Nanoscopium aims to provide multi-length-scale and multitechnique $2 \mathrm{D}$ imaging. This permits zooming in with $\sim 100 \mathrm{~nm}$ spatial resolution onto chosen sample areas from a moderate, approximately micrometre, resolution large field of view scan. The flexible beamline design makes it possible, in a straightforward manner, to optimize the scanning parameters, such as the total measurement time, scanned sample area (some millimetres to nanometre range), resolution $(1-0.1 \mu \mathrm{m})$ and intensity (approximately two orders of magnitude) depending on the experimental needs (degree of coherence, analytical sensitivity, spatial resolution, detector saturation) without any realignment of the sample or the main beamline optics. The main limitation of the fast multi-technique measurements comes from the linearity and throughput limitation of the recently available detectors, especially that of 2D pixel detectors.

Fast 3D scanning multi-technique tomography is accessible at the beamline. We introduced a new measurement strategy for tomography measurements: as a first step, the coarse 3D elemental distribution and morphological structure of the whole sample was obtained from limited angular projections. This was used to identify an interesting area for higher-resolution tomography based on major morphological and elemental distribution features, invisible by optical microscopy. Sub-micrometric resolution XRF tomography is possible in the case of smaller samples or by developing local tomography. The ultimate resolution can be obtained by coherent diffraction. This would open up the possibility of hierarchical length-scale tomography.

These imaging techniques permit studying the modalities of interconnections of sample features of different length-scales, performing statistically significant measurements, and identifying rare events in bulk samples. The development of useroriented software for the treatment of multi-technique imaging and tomography data sets and self-absorption correction for XRF measurements is in progress and is a crucial requirement for the success of the beamline.

The first test experiments showed that the analytical characteristics of the beamline are matching well the requirements of the typical geological and paleo-geological applications expected at the beamline. The first XANES measurements proved the good energy calibration stability of the DCM and the feasibility of nano-XANES in geological samples. As the figure of merit of measurement speed, spatial resolution and appropriate contrast depends on the analysed sample type and measurement set-up, as a next step other representative samples, for example from the field of biology, will be analysed at the beamline.

\section{Acknowledgements}

The authors are grateful for the continuous help and generous support of the Support Groups of Synchrotron Soleil. We thank I. Mohacsi (Synchrotron Soleil, France, and PSI, Switzerland) for providing the standard samples.

\section{References}

Arnison, M. R., Larkin, K. G., Sheppard, C. J. R., Smith, N. I. \& Cogswell, C. J. (2004). J. Microsc. 214, 7-12.

Benabderrahmane, C., Berteaud, P., Valléau, M., Kitegi, C., Tavakoli, K., Béchu, N., Mary, A., Filhol, J. M. \& Couprie, M. E. (2012). Nucl. Instrum. Methods Phys. Res. A, 669, 1-6.

Bordessoule, M. (2012). J. Phys. Conf. Ser. 425, 192018.

Boye, P., Feldkamp, J. M., Patommel, J., Schwab, A., Stephan, S., Hoppe, R., Schroer, C. G., Burghammer, M., Riekel, C., van der Hart, A. \& Küchler, M. (2009). J. Phys. Conf. Ser. 186, 012063.

Bunk, O., Bech, M., Jensen, T. H., Feidenhans'l, R., Binderup, T., Menzel, A. \& Pfeiffer, F. (2009). New J. Phys. 11, 123016.

Chen, S. et al. (2014). J. Synchrotron Rad. 21, 66-75.

Chu, Y. S. (2010). Preliminary Design Report for the Hard X-ray $(H X N)$ Nanoprobe Beamline. Report LT-C-XFD-HXN-PDR-001. National Synchrotron Light Source II, Brookhaven National Laboratory, USA.

Chumakov, A. I., Sergeev, I., Celse, J.-P., Rüffer, R., Lesourd, M., Zhang, L. \& Sánchez del Río, M. (2014). J. Synchrotron Rad. 21, 315-324.

De Andrade, V. J., Ganne, J., Dubacq, B. C. G., Ryan, C. G. F., Bourdelle, F. A., Plunder, A., Falkenberg, G. \& Thieme, J. (2014). J. Phys. Conf. Ser. 499, 012012.

De Andrade, V., Thieme, J., Northrup, P., Yao, Y., Lanzirotti, A., Eng, P. \& Shen, Q. (2011). Nucl. Instrum. Methods Phys. Res. A, 649, 4648.

Desjardins, K., Hustache-Ottini, S., Polack, F., Moreno, T., Dubuisson, J. M., Chubar, O. \& Delmotte, F. (2007). AIP Conference Proceedings of Ninth International Conference on Synchrotron Radiation Instrumentation edited by J. Y. Choi and S. Rah. Melville: American Institute of Physics.

Desjardins, K., Pomorski, M. \& Morse, J. (2014). J. Synchrotron Rad. 21, 1217-1223.

Holler, M., Diaz, A., Guizar-Sicairos, M., Karvinen, P., Färm, E., Härkönen, E., Ritala, M., Menzel, A., Raabe, J. \& Bunk, O. (2014). Sci. Rep. 4, 3857.

Holler, M., Raabe, J., Diaz, A., Guizar-Sicairos, M., Quitmann, C., Menzel, A. \& Bunk, O. (2012). Rev. Sci. Instrum. 83, 073703.

Holt, M., Harder, R., Winarski, R. \& Rose, V. (2013). Annu. Rev. Mater. Res. 43, 183-211.

Hornberger, B., de Jonge, M. D., Feser, M., Holl, P., Holzner, C., Jacobsen, C., Legnini, D., Paterson, D., Rehak, P., Strüder, L. \& Vogt, S. (2008). J. Synchrotron Rad. 15, 355-362.

Hu, Q., Aboustait, M., Ley, M. T., Hanan, J. C., Rose, V. \& Winarski, R. (2014). Acta Mater. 77, 173-182.

Huang, R., Bilderback, D. H. \& Finkelstein, K. (2014). J. Synchrotron Rad. 21, 366-375.

Igarashi, N., Ikuta, K., Miyoshi, T., Matsugaki, N., Yamada, Y., Yousef, M. S. \& Wakatsuki, S. (2008). J. Synchrotron Rad. 15, 292295.

Johnson, I., Bergamaschi, A., Buitenhuis, J., Dinapoli, R., Greiffenberg, D., Henrich, B., Ikonen, T., Meier, G., Menzel, A., Mozzanica, A., Radicci, V., Satapathy, D. K., Schmitt, B. \& Shi, X. (2012). J. Synchrotron Rad. 19, 1001-1005. 
Jonge, M. D. de, Ryan, C. G. \& Jacobsen, C. J. (2014). J. Synchrotron Rad. 21, 1031-1047.

Kak, A. C. \& Slaney, M. (1988). Principles of Computerized Tomographic Imaging. IEEE Press.

Kaulich, B., Thibault, P., Gianoncelli, A. \& Kiskinova, M. (2011). J. Phys. Condens. Matter, 23, 083002.

Kewish, C. M., Polack, F., Signorato, R. \& Somogyi, A. (2013). Proc. SPIE, 8851, 88510G.

Kim, J., Lauer, K., Yan, H., Chu, Y. S. \& Nazaretski, E. (2013). Rev. Sci. Instrum. 84, 035006.

Kottler, C., David, C., Pfeiffer, F. \& Bunk, O. (2007). Opt. Express, 15, $1175-1181$.

Koyama, T., Takano, H., Konishi, S., Tsuji, T., Takenaka, H., Ichimaru, S., Ohchi, T. \& Kagoshima, Y. (2012). Rev. Sci. Instrum. 83, 013705.

Krüger, S. P., Neubauer, H., Bartels, M., Kalbfleisch, S., Giewekemeyer, K., Wilbrandt, P. J., Sprung, M. \& Salditt, T. (2012). J. Synchrotron Rad. 19, 227-236.

Li, J. W., Matias, E., Chen, N., Kim, C.-Y., Wang, J., Gorin, J., He, F., Thorpe, P., Lu, Y., Chen, W. F., Grochulski, P., Chen, X. B. \& Zhang, W. J. (2011). J. Synchrotron Rad. 18, 109-116.

Martinez-Criado, G., Segura-Ruiz, J., Chu, M. H., Tucoulou, R., López, I., Nogales, E., Mendez, B. \& Piqueras, J. (2014). Nano Lett. 14, 5479-5487.

Maser, J., Lai, B. \& Buonassisi, T. (2013). Abstract, TMS 2013, 142nd Annual Meeting and Exhibition, 3-7 March 2013, San Antonio, Texas, USA.

Medjoubi, K., Bucaille, T., Hustache, S., Bérar, J.-F., Boudet, N., Clemens, J.-C., Delpierre, P. \& Dinkespiler, B. (2010). J. Synchrotron Rad. 17, 486-495.

Medjoubi, K., Leclercq, N., Langlois, F., Buteau, A., Lé, S., Poirier, S., Mercère, P., Sforna, M. C., Kewish, C. M. \& Somogyi, A. (2013). J. Synchrotron Rad. 20, 293-299.

Meents, A., Reime, B., Stuebe, N., Fischer, P., Warmer, M., Goeries, D., Roever, J., Meyer, J., Fischer, J., Burkhardt, A., Vartiainen, I., Karvinen, P. \& David, C. (2013). Proc. SPIE, 8851, 88510K.

Menzel, A., Kewish, C. M., Kraft, P., Henrich, B., Jefimovs, K., VilaComamala, J., David, C., Dierolf, M., Thibault, P., Pfeiffer, F. \& Bunk, O. (2010). Ultramicroscopy, 110, 1143-1147.

Mimura, H., Handa, S., Kimura, T., Yumoto, H., Yamakawa, D., Yokoyama, H., Matsuyama, S., Inagaki, K., Yamamura, K., Sano, Y., Tamasaku, K., Nishino, Y., Yabashi, M., Ishikawa, T. \& Yamauchi, K. (2009). Nat. Phys. 6, 122-125.

Mimura, H., Matsuyama, S., Yumoto, H., Hara, H., Yamamura, K., Sano, Y., Shibahara, M., Endo, K., Mori, Y., Nishino, Y., Tamasaku, K., Yabashi, M., Ishikawa, T. \& Yamauchi, K. (2005). Jpn. J. Appl. Phys. 144, L539-L542.

Mohacsi, I., Karvinen, P., Vartiainen, I., Guzenko, V. A., Somogyi, A., Kewish, C. M., Mercere, P. \& David, C. (2014). J. Synchrotron Rad. 21, 497-501.

Mohacsi, I., Vartiainen, I., Guizar-Sicairos, M., Karvinen, P., Guzenko, V. A., Müller, E., Färm, E., Ritala, M., Kewish, C. M., Somogyi, A. \& David, C. (2015). Opt. Express, 23, 776-786.

Moreno, T. \& Idir, M. (2001). J. Phys. IV, 11, 527.
Nazaretski, E., Kim, J., Yan, H., Lauer, K., Eom, D., Shu, D., Maser, J., Pešić, Z., Wagner, U., Rau, C. \& Chu, Y. S. (2013). Rev. Sci. Instrum. 84, 033701.

Nazaretski, E., Lauer, K., Yan, H., Bouet, N., Zhou, J., Conley, R., Huang, X., Xu, W., Lu, M., Gofron, K., Kalbfleisch, S., Wagner, U., Rau, C. \& Chu, Y. S. (2015). J. Synchrotron Rad. 22, 336-341.

Ribbens, M., Dubuisson, J. M. \& Somogyi, A. (2013). Synchrotron Soleil Highlights 130, http://www.highlights-synchrotron-soleil.fr/ Highlights-2013-booklet/\#130/z.

Ryan, C. G., Kirkham, R., Hough, R. M., Moorhead, G., Siddons, D. P., de Jonge, M. D., Paterson, D. J., de Geronimo, G., Howard, D. L. \& Cleverley, J. S. (2009). Nucl. Instrum. Methods Phys. Res. A, 619, 1.

Schroer, C. G., Boye, P., Feldkamp, J. M., Patommel, J., Samberg, D., Schropp, A., Schwab, A., Stephan, S., Falkenberg, G., Wellenreuther, G. \& Reimers, N. (2010). Nucl. Instrum. Methods Phys. Res. A, 616, 93-97.

Sforna, M. C., Philippot, P., Somogyi, A., van Zuilen, M. A., Medjoubi, K., Schoepp-Cothenet, B., Nitschke, W. \& Visscher, P. T. (2014). Nat. Geosci. 7, 811-815.

Siewert, F., Buchheim, J., Boutet, S., Williams, G. J., Montanez, P. A., Krzywinski, J. \& Signorato, R. (2012). Opt. Express, 20, 45254536.

Simos, N., Chu, Y. S., Broadbent, A., Nazaretski, E., Margulies, L., Dyling, O., Shen, Q. \& Fallier, M. (2011). AIP Conf. Proc. 1365, 148-151.

Somogyi, A., Kewish, C. M., Polack, F. \& Moreno, T. (2011). AIP Conf. Proc. 1365, 57-60.

Somogyi, A., Medjoubi, K., Kewish, C. M., Le Roux, V., Ribbens, R., Baranton, G., Polack, F. \& Samama, J. P. (2013). Proc. SPIE, 8851, 885104.

Somogyi, A., Polack, F. \& Moreno, T. (2010). AIP Conf. Proc. 1234, 395-398.

Thibault, P. \& Menzel, A. (2013). Nature (London), 494, 68-71.

Vila-Comamala, J., Gorelick, S., Färm, E., Kewish, C. M., Diaz, A., Barrett, R., Guzenko, V. A., Ritala, M. \& David, C. (2011). Opt. Express, 19, 175-184.

Vogt, S. \& Lanzirotti, A. (2013). Synchrotron Radiat. News, 26, 32 38.

Winarski, R. P., Holt, M. V., Rose, V., Fuesz, P., Carbaugh, D., Benson, C., Shu, D., Kline, D., Stephenson, G. B., McNulty, I. \& Maser, J. (2012). J. Synchrotron Rad. 19, 1056-1060.

Winn, B. et al. (2000). J. Synchrotron Rad. 7, 395-404.

Yan, H. \& Chu, Y. S. (2013). J. Synchrotron Rad., 20, 89-97.

Yan, H., Rose, V., Shu, D., Lima, E., Kang, H. C., Conley, R., Liu, C., Jahedi, N., Macrander, A. T., Stephenson, G. B., Holt, M., Chu, Y. S., Lu, M. \& Maser, J. (2011). Opt. Express, 19, 1506915076 .

Zhang, L., Lee, W.-K., Wulff, M. \& Eybert, L. (2003). J. Synchrotron Rad. 10, 313-319.

Zhang, L., Sánchez del Río, M., Monaco, G., Detlefs, C., Roth, T., Chumakov, A. I. \& Glatzel, P. (2013). J. Synchrotron Rad. 20, 567580 . 